\title{
SKETCHING: PENSAMENTO VISUAL E REPRESENTAÇÃO DE IDEIAS
}

\author{
Cínthia Kulpa \\ Universidade Federal do Rio Grande do Sul \\ cinthia.kulpa@gmail.com \\ Lauren Carús \\ Universidade Federal do Rio Grande do Sul \\ laucarus@gmail.com \\ Patricia Hartmann \\ Universidade Federal do Rio Grande do Sul \\ contato@patriciahartmann.com
}

Resumo: O ensino da representação gráfica através do sketching é um dos fundamentos dos cursos de Design. A capacidade de elaborar um sketch está diretamente relacionada com a construção do pensamento visual, aquele que precede a própria formação do conceito de projeto. Este trabalho descreve a criação e a aplicação de uma metodologia para o ensino de sketching na disciplina Análise e Representação da Forma II dos cursos de Design Visual e de Produto da UFRGS. A metodologia proposta tem o objetivo de aprimorar o entendimento dos alunos sobre os princípios de construção do sketch e de suas técnicas através de uma atuação colaborativa entre professores e alunos visando torná-los mais autônomos e confiantes. O processo que foi apresentado neste artigo impactou na ampliação dos canais de comunicação tradicionais no ensino desta disciplina, uma vez que este se apropriou de diferentes mídias sociais digitais para facilitar a convivência e estreitar o relacionamento professor/aluno. Os resultados apontam para uma melhora significativa no entendimento e no aproveitamento do conteúdo pelos alunos, otimizando os seus trabalhos práticos e conduzindo-os para um domínio maior das ferramentas de desenho. Finalmente, o uso desta metodologia gerou reflexos positivos na qualidade dos sketches apresentados pelos alunos ao longo do semestre.

Palavras-chave: sketch, design, metodologia de ensino.
Abstract: The graphic representation's teaching through sketching is one of the foundations of Design courses. The ability to draw a sketch has been directly related to the construction of visual thinking, which often precedes the design concept itself. This paper describes the development and implementation of a sketching's methodology in Analysis and Representation of Form II in Visual and Product Design courses at UFRGS. The proposed methodology aims to enhance students' understanding on the sketch construction principles and its techniques through a 
collaborative activity between teachers and students aiming to make them more independent and confident. The process presented in this article impacted on the expansion of traditional communication channels in the teaching, since appropriated different digital social media in order to facilitate familiarity between the teachers and student. The results point to a significant improvement in the content 's understanding and use by students, optimizing their practical work and leading them to better drawing tools' domain. Finally, this methodology's use has generated a positive impact on the sketches' quality submitted by students throughout the semester.

Keywords: sketch, design, teaching methodology.

\section{INTRODUÇÃO}

A representação gráfica de um objeto tem grande importância na formação dos Designers. Sendo assim, as disciplinas que ensinam o desenho são uma parte essencial das bases de capacitação destes futuros profissionais. Ademais, é nesse contexto que o desenho se torna uma ferramenta de comunicação, tendo como uma de suas principais funções a consolidação de uma ideia de modo a simplificar o seu entendimento (PIPES, 2010). Pode-se dizer que o desenho é um registro imediato da imagem mental de quem está projetando, visando orientar a compreensão de um produto que se encontra em fase de concepção (POEIRAS, 2009 e FONSECA 2013).

O termo "sketch" é utilizado no Design, para denominar o desenho simplificado, rápido ou inacabado que possui uma linguagem visual própria, chamada de sketching, utilizada pelos designers como forma de representação gráfica. A capacidade de se fazer um sketch é uma das habilidades mais valorizadas entre os designers, uma vez que é considerada uma das maneiras mais rápidas para aproximarse dos problemas, explorar os conceitos e desenvolver possíveis soluções utilizando o papel, a mídia digital ou até mesmo combinando-os (SJÖLEN; OLOFSSON, 2005).

Atualmente, devido à grande quantidade de informações disponíveis na internet, a cada momento surgem inúmeros vídeos tutoriais e cursos online que objetivam apresentar os conhecimentos necessários para sketch. No entanto, existem diferenças entre a informação disponível e o conhecimento aplicável, e este é o maior desafio no ensino das novas gerações (ONTORIA PEÑA; GÓMEZ; RUBIO, 2004, p. 22, apud FERNANDES, 2015). Nesse contexto, a evolução dos meios digitais tecnológicos está remodelando a educação e estabelecendo uma nova dinâmica de ensino e de aprendizagem. Os ambientes virtuais de aprendizagem (AVAs), a aprendizagem assistida por computador (AAC) e o ensino a distância (EaD) modificaram as práticas pedagógicas refletindo diretamente nas disciplinas que ensinam o sketching (PIEDRAS et al., 2011 e FERNANDES, 2015). Piedras (et al., 2011) afirma que a universidade se tornou o local onde as informações disponíveis precisam ser compreendidas, uma vez que se reflete em todo o processo educativo dos alunos. E com isso, é necessário que o professor assuma uma nova postura prática-didática, dando origem a novas metodologias de ensino.

Com isso, questiona-se qual é a melhor forma de conduzir o ensino do sketch no ambiente educacional e quais podem ser as práticas aplicadas. Além disso, seria 
possível propor e aplicar uma nova abordagem para o ensino do sketch nos cursos de graduação em Design buscando melhorar as habilidades de desenho do aluno? Este trabalho busca apresentar o desenvolvimento de uma abordagem metodológica juntamente com seus resultados, proposta para a disciplina Análise e Representação da Forma II (ARF II), a qual é responsável pelo ensino do sketch, e que está inserida na grade curricular dos cursos de Design (Visual e Produto) da Universidade Federal do Rio Grande do Sul (UFRGS). A partir da criação de atividades com diferentes complexidades de domínio do sketch, os alunos puderam vivenciar práticas criativas e alcançar melhorias significativas no próprio desempenho, auxiliando nos futuros desafios que alunos enfrentarão durante os processos de projeto.

\section{O SKETCHING NO ÂMBITO DO DESIGN}

O designer desempenha uma atividade especializada capaz de desenvolver ou aprimorar produtos e serviços, atuando em campos interdisciplinares e fazendo o uso de diversas áreas do conhecimento: as artes, a ciência, a tecnologia e a criatividade, por exemplo. Com base nas Diretrizes Curriculares Nacionais do Curso de Graduação em Design (Brasil, 2004), as principais competências e habilidades que o profissional de Design necessita adquirir durante seu período de formação estão relacionadas à "capacidade criativa para propor soluções inovadoras, através do domínio de técnicas e do processo de criação" e à "capacidade para o domínio de uma linguagem própria expressando conceitos e soluções, em projetos, através de representação visual". Por este motivo o sketching pode ser considerado um mecanismo próprio para a construção visual de uma ideia.

O campo da psicologia cognitiva busca explicar a seletividade que se exerce quando representamos o que estamos vendo: o que a memória humana prioriza e como são organizadas informações tais como a luz, a cor e o contorno em padrões, figuras ou formas com significado (GOLDSCHMIDT, 1994). Pensar é, na ciência cognitiva contemporânea, uma ação fortemente relacionada com a linguagem e com a sua aquisição, produção e desenvolvimento. Já o pensamento visual pode ser classificado como uma fase pré-linguística conforme apontado por Goldschmidt (1994): "as crianças formam imagens onde os adultos formam palavras".

Para um leigo, o pensamento visual é equivalente à percepção, isso significa que tanto o registro na mente quanto a representação da informação são construídos através dos sentidos. O esboço rápido de uma determinada informação pode ser utilizado, por exemplo, para elaborar um diagrama, para descrever ideias abstratas ou concretas, para construir mapas ou orientações de localização em ambientes internos ou externos, sejam estes reais ou imaginários. Entretanto, o pensamento visual difere das representações simbólicas porque nem sempre os esboços seguem as ideias na mente, eles muitas vezes precedem as próprias ideias ajudando a formá-las (GOLDSCHMIDT, 1994).

Esse mecanismo de construção visual tem sido reconhecido por projetistas em diversos campos do conhecimento, das artes à engenharia. Segundo Cross (2001, 2011), o design detém uma maneira específica de pensar, conhecer e agir, descrita como uma designerly ways of knowing. Trata-se de uma maneira particular de raciocínio ou de "pensar por projetos" sendo uma habilidade que pode ser ensinada e aprendida. Nesse processo cognitivo, identificado como uma atividade de resolução de 
problemas, os designers iniciam um projeto através de pistas buscando moldar não somente a solução, mas também o próprio problema.

De acordo com esse ponto de vista, Dorst (2004) e Cross (2011) argumentam que há um processo de co-evolução entre o espaço do problema de projeto e o espaço da solução. Para os autores, os designers manipulam e estruturam o problema de projeto ao mesmo tempo em que o solucionam através de constantes iterações (análises, sínteses e avaliações). Ao mover-se no espaço-tempo do projeto, eles podem utilizar técnicas de representação que facilitam o pensamento visual tais como o sketching, a prototipagem rápida e a construção de cenários, entre outras. Essas técnicas permitem que se possa analisar uma situação inicial a partir de suas propriedades funcionais, espaciais ou simbólicas, considerando alguns de seus componentes ou mesmo a entidade como um todo (GOLDSCHMIDT, 1994). Por esse motivo, o modo de pensar por projetos está diretamente relacionado aos mecanismos de construção do pensamento visual, aqueles que precedem a própria formação do conceito de projeto. Para Goldschmidt (1994), isso significa que o esboço pode preceder a própria ideia, uma vez que o aprimoramento deste auxilia na formação de uma ideia completa e na sua respectiva representação.

Pensando no contexto educacional, é através de uma conversação reflexiva que o aluno pode aprender com a representação visual de suas ideias - o desenhista informa e ao mesmo tempo é informado pelo próprio desenho. As aulas em formato de atelier, onde o aluno tem as atividades práticas como eixo fundamental da disciplina, permitem esse espaço de reflexão entre o desenhista e o seu próprio desenho. Entretanto, o autor não descreve quais poderiam ser os métodos, técnicas e/ou instrumentos necessários para estimular e facilitar esse diálogo e especialmente qual poderia ser a atuação do educador neste processo. De modo geral, o formato de atelier reproduz a prática do mestre e do aprendiz, com o processo de aprendizagem ocorrendo a partir da observação e da prática.

Uma vez que a linguagem do sketching é considerada facilitadora do processo cognitivo de pensamento visual, é importante pesquisar e aplicar abordagens metodológicas adequadas à construção desta técnica no contexto educacional. Na próxima seção será apresentada a disciplina Análise e Representação da Forma II, o conteúdo programático utilizado anteriormente, os problemas observados e a metodologia proposta/implementada juntamente com os resultados.

\section{A DISCIPLINA DE ANÁLISE E REPRESENTAÇÃO DA FORMA II}

O curso de Design da UFRGS forma profissionais habilitados em Design de Produto e Design Visual. De acordo com a $\mathrm{CGD}^{1}$, as práticas pedagógicas são pluridisciplinares, centradas no desenvolvimento da criatividade, na ênfase da autonomia do aluno, na flexibilidade e na polivalência. Ademais, o ensino é embasado na prática de projetos, associando inovação e subjetividade ao processo de criação, assim como a compreensão dos materiais, dos processos e dos mecanismos de projeto, visando promover a aproximação dos setores produtivos, externos ao meio universitário.

A disciplina ARF II, está situada na segunda etapa do curso, tem caráter

\footnotetext{
${ }^{1}$ Comissão de Graduação do Design - UFRGS.

www.ufrgs.br/ufrgs/ensino/graduacao/cursos/exibeCurso?cod_curso=524
} 
obrigatório, é realizada em 4 créditos e compreende uma carga horária de 60 horas. Tem por objetivo possibilitar aos alunos, alternativas de treinamento em técnicas específicas para o registro e a representação gráfica através do sketching. Contribuindo, desta forma, para o desenvolvimento do raciocínio especulativo próprio do processo projetual dos alunos. No que se refere à percepção visual como meio de compreensão da estrutura formal dos objetos, busca desenvolver as capacidades de observação sistemática e criteriosa, permitindo a geração de novas estruturas através de diferentes interpretações. Também estimula os alunos a compreenderem as distorções do objeto que ocorrem sob a ótica do observador, enfatizando o ensino das perspectivas cônicas como um dos pontos relevantes discutidos em aula (CGD/UFRGS).

As Atividades Práticas (APs) desenvolvidas estão relacionadas aos diversos conteúdos que abrangem o tema Sketching: 1 . dimensões do objeto, tais como, proporção, perspectiva e volumetria; 2 . formas geométricas básicas que constituem o objeto e que levem a uma correta construção tridimensional deste; 3 . linguagem de sketching, empregando materiais, tais como, lápis de cor, giz pastel, marcadores, gouache e outros. Nesta disciplina também são abordados assuntos relacionados ao sketching como meio de expressão, representação, manipulação e comunicação das ideias em todas as etapas de desenvolvimento do processo de projeto; além do tempo de execução e da qualidade de apresentação através da observação, da interpretação e da releitura dos objetos.

\subsection{Metodologia Anterior e Conteúdo Programático}

Anteriormente, a metodologia utilizada em ARF II consistia de aulas expositivas; aulas teórico-práticas; apreciação dos trabalhos realizados; leitura e análise de textos relacionados aos temas abordados; assessoramento dos projetos desenvolvidos pelos alunos; montagem e desenvolvimento de um bloco de desenhos e de um portfólio de sketches. A carga horária dessa disciplina é considerada pequena em relação a grande quantidade de conteúdos que deveriam ser abordados. Com isso, durante quatro semestres consecutivos (2011/01 e 02, 2012/01 e 02) foram observados e registrados diversos problemas e dificuldades vivenciadas pelos alunos. Essas informações, juntamente com os resultados das atividades realizadas e entregues por eles, reforçou a necessidade de revisão da metodologia utilizada, assim como da dinâmica do conteúdo programático empregado.

Inicialmente, era proposto um tempo reduzido para cada uma das diferentes atividades práticas (Quadro 1), as aulas expositivas não podiam ser muito exploradas para não ocuparem o tempo das atividades práticas e ainda, o assessoramento a todos os alunos, em aula, se tornava difícil quando muitos alunos encontravam dificuldades em desenvolver alguma atividade mais elaborada.

De acordo com o Quadro 1, observa-se que a maioria das APs eram realizadas em apenas uma aula. Quando o aluno encontrava problemas ou dificuldades em dominar a AP, seja por conta das ferramentas, da interpretação da proposta, ou outra causa; o resultado do sketch ficava prejudicado, uma vez que o aluno não teria mais possibilidade de corrigir o problema, devido à falta de tempo, gerando sentimentos de frustração e insegurança no aluno. Alguns alunos não conseguiam executar a proposta em apenas uma aula e com isso, acumulavam sketches de uma atividade junto à outra, impedindo que tivessem um aproveitamento total da atividade proposta em aula. 
Os alunos que tinham dificuldades em visualizar espacialmente os objetos ou ideias, refletindo assim na representação dos objetos, evitavam realizar as atividades práticas em aula, para não terem seus sketches expostos e/ou comentados. Logo, o trabalho de assessoramento dos docentes e do monitor não ocorria, pois não havia o sketch a ser avaliado. Segundo Booth (2016), os fatores que dificultam o ensino desta técnica podem estar relacionados a inibição do aluno. $O$ autor classifica a resistência em desenhar a diferentes fontes de inibição: pessoal, se dá quando o aluno busca desenhar o sketch perfeito na primeira tentativa, e acaba frustrando-se quando não o obtém; intelectual, relacionada com a crença de que o desenho não é relevante para o design; e social/comparativa a partir do medo que o aluno enfrenta de ser julgado pelos outros e/ou comparado com o colega.

Algumas aulas tinham mais de uma AP, com tempos determinados de 10 a 2 minutos cada uma, o que resultava em sketches incompletos, imprecisos e com problemas formais. A propósito, de acordo com o objetivo da atividade, estes sketches não podiam ser refeitos em outra oportunidade ou local, pois a proposta era trabalhar a espontaneidade e melhorar os seus reflexos com o esboço livre. Porém, os alunos viam esses resultados como falta de habilidade e de incompetência, já que estavam em desacordo com os originais. Outras APs dividiam o tempo com aulas expositivas ou com a apreciação dos trabalhos realizados e montagem de bloco e portfólio. A atenção dos alunos se voltava para a AP que não tiveram tempo de terminar, muitas vezes gerando uma perda na concentração dos conteúdos subsequentes. Ademais, em APs mais complexas, eram utilizados poucos objetos como referência para o desenho, formando grupos de 08 alunos em média. Em consequência disso, os alunos ficavam muito afastados dos seus objetos interferindo na percepção dos detalhes de encaixes, texturas, proporção, espessuras, e também impedindo a manipulação direta dos objetos como experiência sensorial. Piaget (1977 apud Pietras et al., 2011) afirma que a experiência do aluno com o produto real auxilia na formação do conhecimento aplicável.

Quadro 1: Atividades Práticas de Sketch de ARF II - 2011/01.

\begin{tabular}{|c|c|c|c|}
\hline $\begin{array}{l}\text { № de } \\
\text { Aulas }\end{array}$ & Atividade Prática de Sketch & № de Objetos & $\begin{array}{l}\text { No de } \\
\text { Pranchas }\end{array}$ \\
\hline 01 & Sondagem & 01 por aluno & 01 \\
\hline 01 & Exercícios diversos & - & livre \\
\hline 04 & $\begin{array}{l}\text { Biônica - Observação, decomposição e representação de } \\
\text { elemento da natureza }\end{array}$ & 01 por aluno & 04 \\
\hline 02 & Objeto oculto sinples e composto & 01 por aluno & 04 \\
\hline 02 & Representação de objeto desmontado & 01 por aluno & 01 \\
\hline 02 & Observação c/ diferentes técnicas e ângulos - tempo determinado & 01 por grupo* & 12 \\
\hline 02 & Observação c/ diferentes ferramentas - tempo determinado & 01 por grupo* & 02 \\
\hline 02 & Representação de objeto em vista explodida & 01 por grupo* & 02 \\
\hline 02 & Estudos de diagramação & - & livre \\
\hline 02 & Representação de objeto em corte & 01 por grupo* & 01 \\
\hline 03 & Diagrama funcional & 01 por aluno & 03 \\
\hline 03 & $\begin{array}{l}\text { Redesign - Observação, deformação, novos estudos e } \\
\text { representação da alternativa escolhida }\end{array}$ & 01 por grupo* & 03 \\
\hline 04 & $\begin{array}{l}\text { Sistema de informação - Exercício de letras e diagramação, } \\
\text { planejamento, execução e representação da alternativa escolhida }\end{array}$ & - & 03 \\
\hline 29 & \multicolumn{2}{|c|}{ *grupos de +-08 alunos } & 36 \\
\hline
\end{tabular}


Fonte: Elaborado pelas autoras, com base na pesquisa realizada.

Outros problemas observados foram relacionados às avaliações, uma vez que foram considerados critérios que podem ser subjetivos ao processo, tais como: Interesse e Motivação, Assiduidade, Pontualidade e Qualidade das Propostas Apresentadas, pois tinham mesmo peso que os outros critérios. A Prova Prática, 0 Portfólio (com os sketches finais) e o Bloco (com os estudos) tinham mesmo peso e eram entregues no meio e no final do semestre. Contudo, observou-se que alguns alunos eram desinteressados, não eram pontuais e nem assíduos, se saiam muito mal nas provas práticas e mesmo assim tinham médias finais boas, já que apresentavam o Bloco de Estudos e o Portfólio bem feitos.

Seguem alguns sketches (Figura 1) considerados como bons resultados realizados por alunos que seguiam a metodologia anterior:

Figura 1: Sketches de alunos com a metodologia anterior

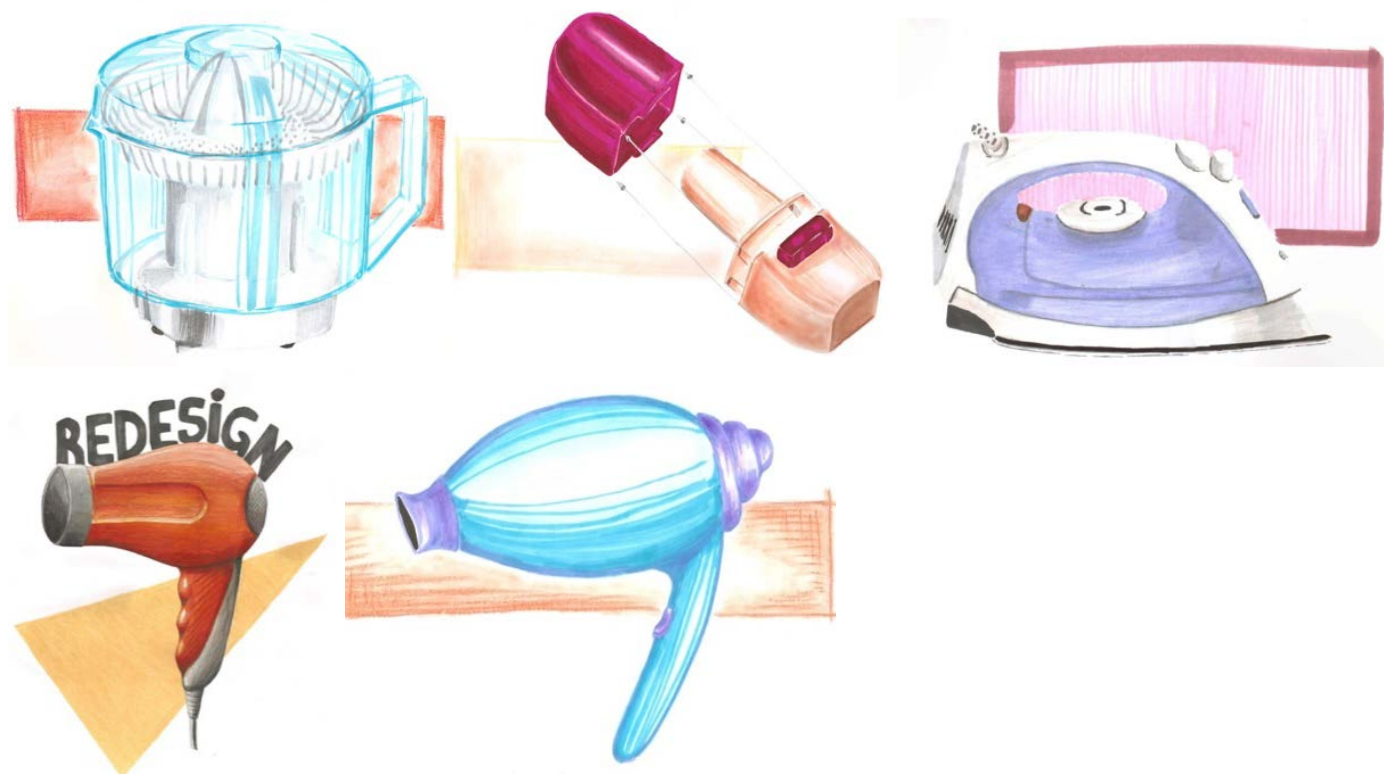

Fonte: Elaborado pelas autoras, com base na pesquisa realizada.

Cabe ressaltar ainda, que em ARF II o aproveitamento dos alunos está diretamente relacionado ao domínio que eles fazem dos conhecimentos abordados nas disciplinas do primeiro semestre do curso. Apropriar-se corretamente destes conhecimentos tais como visão espacial, representação formal, percepção da luz e da sombra, construção das perspectivas, composição, identificação dos sólidos geométricos na forma, e outros, é fundamental para o bom desempenho desses alunos - em ARF II não há possibilidade de rever os conceitos devido ao pouco tempo disponível.

\subsection{Abordagem Metodológica Proposta}

A partir de 2013/01 a disciplina passou por sensíveis mudanças tanto na metodologia empregada, quanto no conteúdo programático e avaliações. Devido a uma clareza maior por parte dos docentes responsáveis pela disciplina, sobre os problemas enfrentados pelos alunos e a importância do sketching no desenvolvimento 
profissional deles, a metodologia proposta incorporou as aulas expositivas às aulas práticas, apresentando os conceitos apropriados enquanto os alunos experienciam os problemas através do sketching nas Atividades Práticas (APs). A apreciação dos trabalhos realizados foi eliminada, diminuindo a carga emocional dos alunos em relação ao medo de exposição enquanto aprendizes. A leitura e a análise de textos relacionados aos temas abordados passaram a fazer parte dos canais de comunicação que foram criados, gerando outras fontes de aproximação, diálogo e apelo. 0 assessoramento dos projetos desenvolvidos pelos alunos, passou a ser mais efetivo devido ao aumento no tempo de cada AP. A montagem e desenvolvimento do Portfólio de sketches se manteve, mas o Bloco não é mais avaliado.

Tornou-se necessário implantar novas APs mais dinâmicas, buscando resultados de sketch com melhor qualidade, uma vez que os alunos não tinham tempo hábil para adquirir todos os conhecimentos transmitidos imediatamente e ao mesmo tempo precisavam aumentar a confiança na realização dos sketches (Quadro 2). Dessa forma foi possível redistribuir e aumentar os tempos de cada AP e criar uma rotina de trabalho possível de ser executada pelos alunos nesse momento da graduação.

Quadro 2: Atividades Práticas de Sketches de ARF II - 2015/01.

\begin{tabular}{|c|c|c|c|}
\hline $\begin{array}{l}\text { No de } \\
\text { Aulas }\end{array}$ & Atividade Prática de Sketches & $\begin{array}{l}\text { № de } \\
\text { Objetos }\end{array}$ & $\begin{array}{c}\text { № de } \\
\text { Pranchas }\end{array}$ \\
\hline 01 & Sondagem & 01 por aluno & 01 \\
\hline 01 & Analogia a Natureza - Observação de elemento da natureza & 01 por aluno & 01 \\
\hline 01 & Analogia a Natureza - Decomposição e 3 novos estudos & - & 02 \\
\hline 01 & $\begin{array}{l}\text { Analogia a Natureza - Representação de } 1 \text { alternativa dos novos } \\
\text { estudos }\end{array}$ & - & 01 \\
\hline 02 & Analogia a Natureza - Sketching Final & - & 01 \\
\hline 02 & Objeto oculto simples e revelado & 01 por aluno & 02 \\
\hline 03 & Objeto oculto composto desmontado e revelado & 01 por aluno & 02 \\
\hline 04 & Laboratório de Marcadores & 01 por aluno & 04 \\
\hline 01 & Sketching Renderizado de um Objeto & 01 por aluno & 01 \\
\hline 01 & Texturas Cromado e Madeira & 01 por aluno & 01 \\
\hline 02 & Textura Vidro em Papel Branco e em papel colorido & 01 por aluno & 02 \\
\hline 01 & Sketching de um Objeto com 2 Materiais, no Papel Branco & 01 por grupo* & 01 \\
\hline 01 & Sketching do Objeto trabalhado na Prova & 01 por aluno & 01 \\
\hline 01 & Sketching de um Objeto com 2 Materiais, no Papel Colorido & 01 por grupo* & 01 \\
\hline 02 & Sistema de Informação - observação e elaboração de um cartaz & 01 por aluno & 02 \\
\hline 03 & Redesign de um Objeto - Analogia aos Elementos Marinhos & 01 por grupo* & 03 \\
\hline 03 & Cartaz - Sketching do Alimento para Material promocional & 01 por aluno & 03 \\
\hline 30 & \multicolumn{2}{|c|}{ *grupos de +-04 alunos } & 29 \\
\hline
\end{tabular}

Fonte: Elaborado pelas autoras, com base na pesquisa realizada.

Assim, conforme aparece no Quadro 2, determinou-se que as Atividades de Exercícios Livres e as com Tempo Estipulado, seriam substituídas por mais aulas de Analogia a Natureza e de Sketch de Objeto Oculto e Revelado, Simples e Composto, uma vez que não contribuíam de forma positiva na construção do conhecimento dos alunos conforme apresentado no capítulo anterior. O nome "Biônica" referente à AP de Analogia a Natureza, foi modificado devido ao conceito da biônica não estar 
alinhado ao objetivo da atividade. As aulas de Estudos de Diagramação, Representação de Objeto em Vista Explodida e em Corte, foram substituídas por aulas de Laboratório de Marcadores, para que os alunos pudessem se familiarizar mais com estas ferramentas próprias do sketching. A aula de Estudo de Diagramação não era necessária, visto que este tema está inserido na disciplina de "Estudos Tipográficos". Da mesma forma, identificou-se que as aulas de Vista Explodida e de Corte já são abordadas nas disciplinas de Expressão Gráfica. As aulas de Diagrama Funcional fazem parte das disciplinas de Projeto. Portanto, foram substituídas por aulas de Atividades de desenvolvimento de um Cartaz, para haverem AP que contemplem as duas habilitações (Visual e Produto).

Além disso, foram instituídas as Atividades Complementares (ACs) (Quadro 3) para serem realizadas em casa, com temas bastante diversificados e relacionados com os conteúdos apresentados nas semanas anteriores. As ACs tem uma correção semanal dos sketches, a fim de passar um feedback para os alunos de como eles estão se saindo na interpretação dos objetos desenhados. As ACs devem ser entregues semanalmente, não são aceitas quando estão atrasadas e fazem parte do Portfólio. Isso significa que cada $A C$ que não for entregue diminui a nota do portfólio e isso representa $45 \%$ da média final. Assim, os alunos precisam de disciplina para fazer os sketches semanalmente, exercitando suas aptidões através de APs com diferentes complexidades.

Quadro 3: Atividades Complementares de ARF II

\begin{tabular}{|l|l|l|}
\hline № & \multicolumn{1}{|c|}{ Atividade Complementar } & \multicolumn{1}{|c|}{ Complexidade } \\
\hline 01 & Coroa dos Bixos & Construção de elipses \\
\hline 02 & Controle Remoto & $\begin{array}{l}\text { Sólidos geométricos em perspectiva paralela, gradiente c/ grafite e } \\
\text { proporção }\end{array}$ \\
\hline 03 & Secador de Cabelo & Mudança de plano e cilindros em perspectiva paralela \\
\hline 04 & Moto ou Vespa Real & Plano, tempo restrito e proporção dos elementos componentes \\
\hline 05 & Tradicional Chimarrão Gaúcho & Formato orgânico e inserção de elemento \\
\hline 06 & Cadeira da Sala de Jantar & Detalhamento, marcadores e textura \\
\hline 07 & Colher de Sopa em Cromado & Forma orgânica e marcadores \\
\hline 08 & Caneca com Alça em Madeira & Construção da alça e textura \\
\hline 09 & Copo de Vidro em Papel Colorido & Deformação e transparência \\
\hline 10 & Pacote de Pão Tipo Bisnaguinha & Transparência e papel colorido \\
\hline 11 & Escova com Pasta Dental & Composição e profundidade \\
\hline 12 & Par de Tênis com Cadarços Soltos & Deformação e texturas \\
\hline 13 & Embalagem Tetra Pak & Nenhuma \\
\hline
\end{tabular}

Fonte: Elaborado pelas autoras, com base na pesquisa realizada.

Juntamente com estas mudanças também foi implementada a respectiva disciplina à distância pelo AVA MOODLE, como apoio às aulas presenciais, através de um projeto aprovado no Edital 15 da Secretaria de Educação a Distância/UFRGS. Este projeto gerou uma vaga de bolsista de graduação, o qual pode ser orientado na elaboração e organização de todo o conteúdo da disciplina no ambiente virtual, com dinâmicas diferenciadas, através de vídeos tutoriais, imagens e passo-a-passos, exemplificando e reforçando os temas abordados em aula. No portal da disciplina à distância, as aulas são liberadas para serem visualizadas pelos alunos uma semana antes que ocorra presencialmente para que eles possam ter um contato prévio com o 
conteúdo que será abordado e com isto já iniciem investigações mais apuradas através das percepções das formas, cores, materiais e proporções dos elementos que serão trabalhos como modelos para o sketch.

Atualmente, a disciplina também faz uso de mídias sociais e de canais de comunicação comuns aos alunos, tais como Facebook, Youtube e Pinterest, modificando a dinâmica do ensino de forma a aproximar alunos e professores. Através do Facebook - Grupo Fechado "ARF II", busca-se a colaboração participativa, onde são postados temas interessantes e atuais relacionados à disciplina para serem lidos, enviam-se lembretes importantes e instiga-se os alunos à apresentarem seus sketches às pessoas de suas relações. No Youtube - Canal "Tutorial Sketch ARF II", a motivação se dá através do concurso de tutoriais com votação feita por profissionais renomados na área e com premiação real para os 3 primeiros lugares. O Pinterest - "Sketches" mantém uma pasta contendo diversos sketches realizados por profissionais e por amadores, dando suporte aos conceitos apresentados e desenvolvidos.

As avaliações são baseadas em critérios objetivos, sendo que tanto a Prova Prática quanto o Portfólio (incluindo ACs) são iguais à $45 \%$ da média final. Os outros $10 \%$ da nota final compreende os critérios de Pontualidade e Participação. Como o Bloco é considerado um registro das etapas dos sketches finais e das diferentes técnicas e ferramentas utilizadas, ele passou a não ser mais avaliado.

A seguir apresentamos alguns sketches (Figura 2) considerados adequados que foram realizados por diferentes alunos a partir da nova abordagem metodológica:

Figura 2: Sketches de diferentes alunos com a metodologia atual.

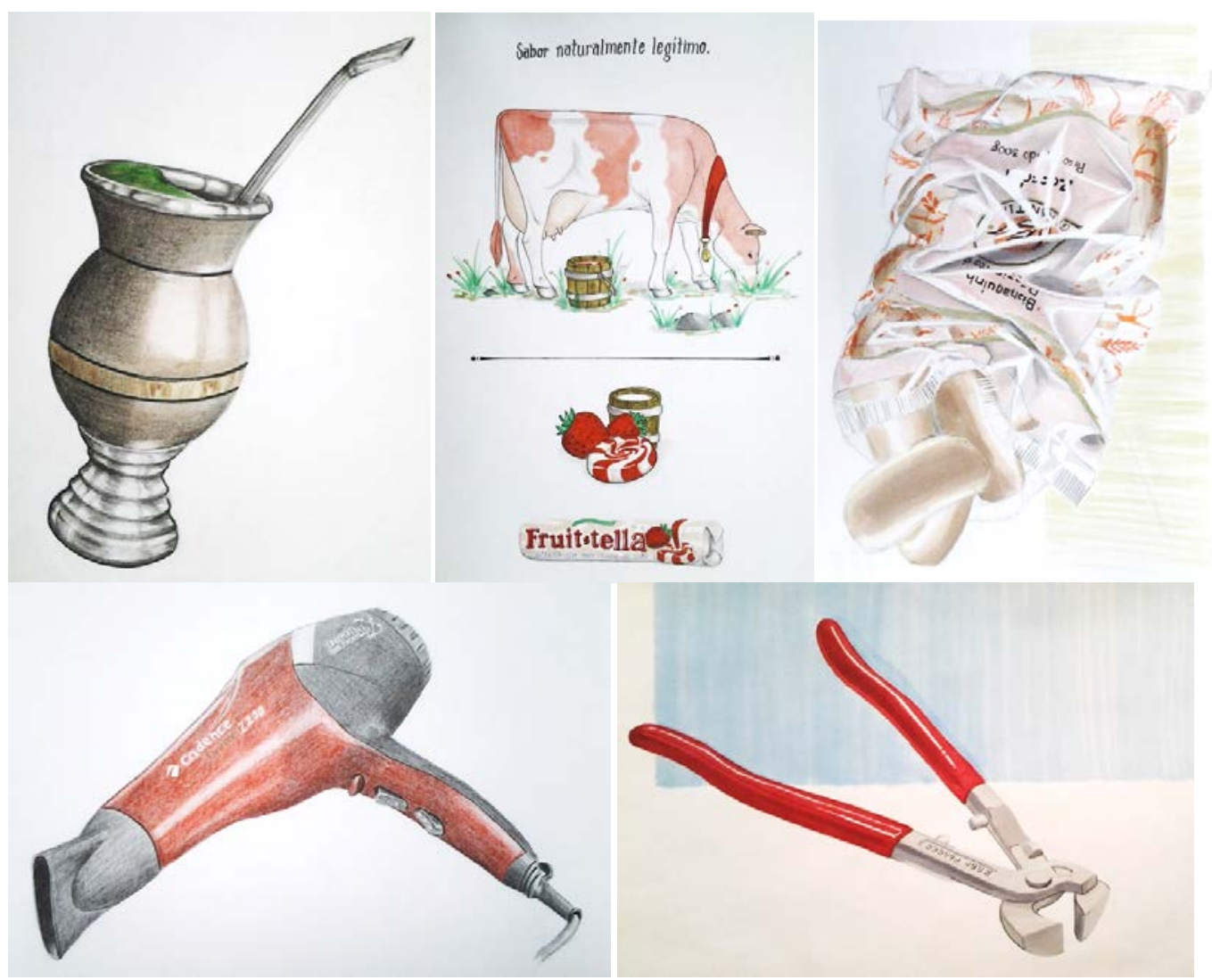




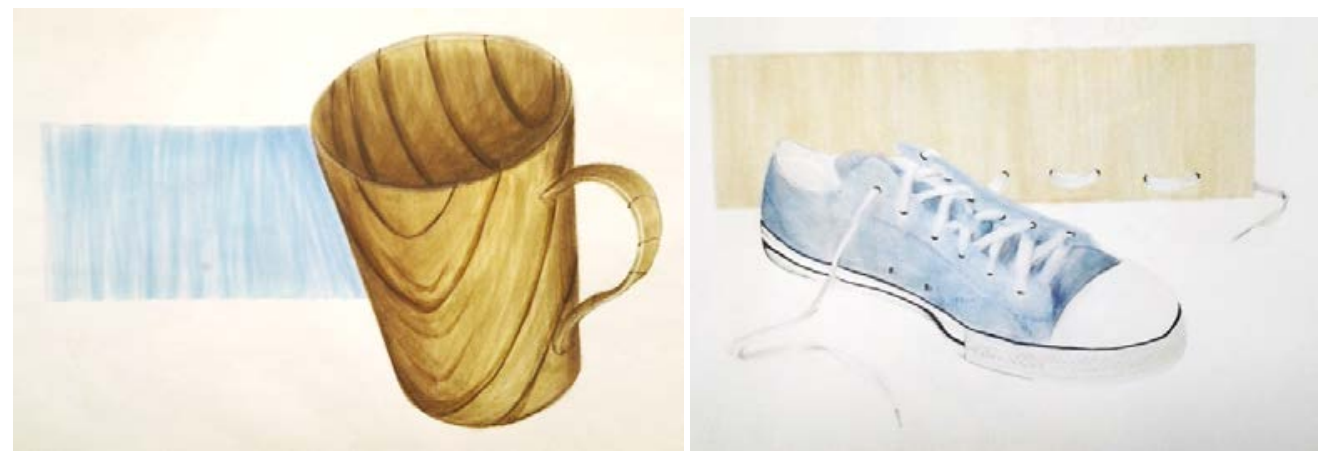

Os resultados têm sido bastante satisfatórios, uma vez que se percebe uma grande motivação por parte dos alunos por acreditarem que eles irão realmente dominar a habilidade do sketching cursando ARF II. Os professores responsáveis pelas disciplinas de Projeto perceberam uma melhoria significativa na qualidade dos sketches na grande maioria dos seus atuais alunos.

\section{CONSIDERAÇÕES FINAIS}

O processo projetual em design possui diversos momentos aos quais podemos associar diferentes tipos de desenho e seus respectivos níveis de complexidade e/ou detalhamento. Os sketches geralmente estão vinculados ao processo da criatividade e por isso existe uma grande preocupação na sua representação. Para o designer, o sketch tem como função auxiliar a exposição de uma ideia e entender as relações espaciais e as estruturas do produto e/ou serviço imaginado (PURCELL, A. T; e GERO, 1998). Porém, nem todos os designers possuem esta habilidade naturalmente. Por isso, é importante que esse conhecimento se estabeleça nas bases da educação profissional dos alunos, pois é uma capacidade que pode ser treinada.

Como destacamos anteriormente, Schön (2000) apresenta uma abordagem projetual que prioriza a intuição, evocando as memórias e as experiências profissionais prévias de cada designer. De acordo com o autor, a atividade projetual pode ser considerada como uma conversa reflexiva com a situação problemática em que se encontra o designer. Trata-se de uma qualidade dinâmica de conhecer-na-ação e de refletir imediatamente sobre o que é criado a partir da expressão visual das ideias em um diálogo entre o designer e o desenho.

Em resposta às questões levantadas neste trabalho, sobre a forma de ensino do sketch no ambiente educacional e quais abordagens metodológicas poderiam facilitar as habilidades de desenho dos alunos, as autoras acreditam que os processos relatados aqui juntamente com a apresentação dos resultados após a sua implementação podem contribuir para o avanço deste tema. As metodologias para o ensino do skecthing devem partir de uma aglutinação de diferentes situações de motivação que habilitem o aluno à pensar intuitivamente através de um esboço, resultando na sua construção visual de uma ideia. Como vimos na seção anterior, o caminho pode ser o uso de técnicas desafiadoras sem exposição e/ou constrangimentos dos alunos aprendizes associado ao uso de múltiplos canais (presenciais e à distância) com auxílio da tecnologia. E a forma contundente de como a disciplina cresceu e se transformou em referência no ensino de sketching, além da comprovação do domínio pleno desta técnica pelos alunos, evidencia a importância em serem criadas novas abordagens que venham a somar com as discutidas neste artigo beneficiando a todos. 


\section{REFERÊNCIAS}

BOОTH, W. J; et al. Interventions for teaching sketching skills and reducing inhibition for novice engineering designers. Design Studies, v. 43, p. 1-23, 2016.

BRASIL, Resolução no5: Diretrizes Curriculares Nacionais do Curso de Graduação em Design. Brasília: DF, 2004.

CROSS, N. Designerly Ways of Knowing: design discipline versus design science. In: Design Issues. v. 17, n. 3, p. 49-55, MIT Press Journals, Cambridge, 2001.

CROSS, N. Design Thinking: Understanding how designers think and work. New York: Berg, 2011.

DORST, K. The Problem of Design Problems. In: The Journal of Design Research, v. 4, n. 2, 2004.

FERNADES, S. Uma proposição metodológica para o ensino de desenho aplicado ao processo criativo em equipe de projeto de produto. 2015. Dissertação (Mestrado). Universidade Federal do Rio Grande do Sul, Programa de Pós-Graduação em Design.

FONSECA, F.; VIZIOLI, S. A representação gráfica na revista projeto \& design. XXI simpósio nacional de geometria descritiva e desenho técnico. X International Conference on Graphics Engineering for Arts and Design. Disponível na internet por http://www.iau.usp.br/pesquisa/grupos/nelac/wpcontent/uploads/2015/01/GRAPHICA2013_massaro_vizioli_A-REPRESENTACAOGRAFICA-NA-REVISTA-PROJETO-DESIGN.pdf Acesso em 14 mai. 2015.

GOLDSCHMIDT, G. On visual design thinking: the vis kids of architecture. In: Design Studies. Vol 15 No 2 April 1994.

JOHNSON, S. Cultura da Interface: Como o Computador Transforma nossa Maneira de Criar e Comunicar. Rio de Janeiro: Editora Jorge Zahar, 2001.

KENSKI, V. M. Tecnologias e ensino presencial e a distância. Campinas São Paulo: Papirus, 2003.

SCHÖN, D. A. Educando o Profissional Reflexivo. Porto Alegre: Artmed, 2000.

OLOFSSON, E.; SJÖLEN, K. Design Sketching: Including an Extensive Collection of Inspiring Sketches by 24 Students at the Umea Institute of Design. Sundsvall: KEEOS Design Books, 2007.

PIEDRAS, E. et al. Representação gráfica digital para o design através de ambientes virtuais de aprendizagem. Novas Tecnologias na Educação. V. 9 № 2, 2011. Disponível na internet por http: <http://seer.ufrgs.br/renote/article/viewFile/25080/14772 > Acesso em 14 mai. 2015.

PIPES, Alan. Desenho para Designers. São Paulo: Blucher, 2010.

POEIRAS, F. Pragmáticas do desenho em design II: a não consciência entre a ideia e a imagem no "exercício" do desenho. Caderno PAR - ESAD. CR, v.1, n.2, p. 10-25, 2009. PURCELL, A. T; e GERO, J. S. Drawings and the design process. Design Studies Vol 19 No 4 October, 1998. 